\title{
Lung function prior to viral lower respiratory tract infections in prematurely born infants
}

\author{
Simon B Drysdale, ${ }^{1}$ Theresa Wilson, ${ }^{1}$ Mireia Alcazar, ${ }^{1}$ Simon Broughton, ${ }^{1}$ \\ Mark Zuckerman, ${ }^{2}$ Melvyn Smith, ${ }^{2}$ Gerrard F Rafferty, ${ }^{1}$ S L Johnston, ${ }^{3}$ \\ Anne Greenough ${ }^{1}$
}

\begin{abstract}
- An additional table is published online only. To view this file please visit the journal online (http://thorax.bmj.com).

${ }^{1}$ Division of Asthma, Allergy and Lung Biology, King's College London, London, UK

${ }^{2}$ South London Specialist Virology Centre \& Health Protection Agency London Regional Laboratory, King's College Hospital, London, UK ${ }^{3}$ Department of Respiratory Medicine, National Heart and Lung Institute, Imperial College London, UK
\end{abstract}

\section{Correspondence to}

Professor Anne Greenough, Neonatal Intensive Care Centre, 4th Floor Golden Jubilee Wing, King's College Hospital, Denmark Hill, London SE5 9RS, UK; anne.greenough@kcl.ac.uk

Received 28 July 2010 Accepted 31 January 2011 Published Online First 28 March 2011

\begin{abstract}
Objective Prematurely born infants who develop respiratory syncytial virus (RSV) lower respiratory tract infections (LRTIS) have lung function abnormalities at follow-up. The aim of this study was to determine whether prematurely born infants who developed symptomatic RSV, or other viral LRTI(s), had poorer premorbid lung function than infants who did not develop LRTIs during the RSV season.
\end{abstract}

Methods Lung function (functional residual capacity (FRC), compliance (Crs) and resistance (Rrs) of the respiratory system) was measured at 36 weeks postmenstrual age. After neonatal unit discharge, nasopharyngeal aspirates were obtained whenever the infants had an LRTI, regardless of whether this was in the community or in hospital. Nasopharyngeal aspirates were examined for RSV A and B, rhinovirus, influenza A and $B$, parainfluenza 1, 2 and 3 , human

metapneumovirus and adenovirus.

Results 159 infants with a median gestational age of 34 (range 23-36) weeks were prospectively followed. 73 infants developed LRTIs: 27 had at least one RSV LRTI and 31 had at least one other viral LRTI, but not an RSV LRTI. Overall, there were no significant differences in the FRC $(p=0.54)$, Crs $(p=0.11)$ or $\operatorname{Rrs}(p=0.12)$ results between those who developed an RSV or other viral LRTI and those who did not develop an LRTI. Infants with RSV or other viral LRTIs who were admitted to hospital compared with those who were not had higher Rrs results ( $p=0.033$ and $p=0.039$, respectively).

Conclusion Diminished premorbid lung function may predispose prematurely born infants to severe viral LRTIs in infancy.

\section{INTRODUCTION}

Respiratory syncytial virus (RSV) infection in previously healthy infants ${ }^{1-4}$ and those born prematurely ${ }^{5}$ is associated with lung function abnormalities at follow-up. The abnormalities include elevated thoracic gas volume and airway resistance at 1 year of age, ${ }^{15}$ airways obstruction in children $^{23}$ and lower forced expiratory volume over $1 \mathrm{~s}$ and maximal expiratory flow at $25 \%$ of forced vital capacity in young adults. ${ }^{4}$ It is possible, however, that those lung function abnormalities at follow-up may reflect that infants who develop symptomatic lower respiratory tract infections (LRTIs) have diminished premorbid lung function. In one study, ${ }^{6}$ term-born infants who developed bronchiolitis in the first year after birth, compared with those who did not, had a non-significant trend to a lower maximal flow at functional residual capacity $\left(\mathrm{V}_{\max }\right.$ FRC) at 5 weeks of age-that is, before they developed bronchiolitis. In addition, in the Tucson Children's Respiratory Study, compared with controls, infants who had wheezing LRTIs in their first year had lower respiratory conductances prior to the $\operatorname{LRTI}^{7}$ and infants who had wheezy LRTIs in the first 3 years had lower premorbid $V_{\max }$ FRCs prior to the LRTI. ${ }^{8}$ Among infants born before 32 weeks of gestation, those who developed an RSV LRTI had a significantly higher resistance of the respiratory system at 36 weeks postmenstrual age (PMA) at follow-up compared with those who did not. ${ }^{\text {' }}$ The symptomatic 'RSV LRTI' group, however, had similar resistance results to the 'RSV-negative LRTI' group, ${ }^{9}$ perhaps suggesting that diminished lung function in prematurely born infants might predispose to other viral LRTIs, as well as RSV LRTI, but the numbers of infants included in the study was small. ${ }^{9}$ Our aim, therefore, was to test, in a larger cohort, the hypothesis that diminished premorbid lung function would predispose prematurely born infants not only to symptomatic RSV LRTIs, but also to other viral LRTIs. In addition, we wished to determine whether infants who developed severe LRTIs (ie, they required hospitalisation) had poorer lung function than those who did require hospitalisation for the LRTI. The results of such a study would be important to determine whether assessment of lung function might be useful to identify a high risk group who could be targeted for prophylaxis against viral infections. As a consequence, we have related premorbid lung function in prematurely born infants to the occurrence of LRTIs. We have studied infants with a wide range of gestational ages, so additionally we could determine whether maturity at birth influenced any functional predisposition to viral LRTIs.

\section{METHODS}

Infants born at $<36$ weeks of gestational age were eligible for entry into the study if they were born prior to the onset of the RSV season in 2008 or 2009. The RSV season was defined as 1 October to 31 March, consistent with the UK experience. ${ }^{10}$ Consecutive infants whose parents gave informed written consent were recruited. The study was approved by the Research Ethics Committee of King's College Hospital NHS Trust.

The infants underwent lung function measurements at 36 weeks PMA while still inpatients on the neonatal unit. The infants were studied while supine and asleep, they were not sedated and none 
was ventilated at the time of study. Lung volume was assessed by measurement of FRC, using a commercially available helium gas dilution system (EBS 2615, Equilibrated Bio Systems, New York, USA). The FRC system contained a $500 \mathrm{ml}$ rebreathing bag, the system reservoir, enclosed in an airtight cylinder, and a helium analyser, with a real-time digital display. A facemask (Rendell Baker, Laerdal Norway, facemask size 0 or 1) was held snuggly over the infant's nose and mouth; silicone putty was used around the mask to achieve an airtight seal. The facemask was connected to the rebreathing bag via a three-way valve. The three-way valve was switched at the end of expiration, so that the infant subsequently breathed from the rebreathing bag. Digital display of the helium dilution curve allowed determination of when equilibration occurred. During the measurement, if there was no change in the helium concentration over a $15 \mathrm{~s}$ period, equilibration was deemed to have occurred. The initial and equilibration helium concentrations were used to calculate FRC, which was corrected for oxygen consumption $(7 \mathrm{ml} / \mathrm{kg} / \mathrm{min})^{11}$ and converted to body temperature and water vapour saturated conditions. FRC was measured at least twice in each infant to obtain two results which were within $10 \%$ of each other. The paired FRC results were then averaged. The mean intrasubject coefficient of variability of the measurement of FRC was $5 \%$.

Compliance (Crs) and resistance (Rrs) of the respiratory system were measured using the single breath occlusion technique. A facemask was placed over the infant's nose and mouth; silicone putty was used around the face mask to ensure an airtight seal. A pneumotachograph (Mercury F10L; GM Engineering, Kilwinning, UK) connected to a differential pressure transducer (range: $\pm 2 \mathrm{~cm} \mathrm{H} \mathrm{H}_{2} \mathrm{O}, \mathrm{MP} 45$, Validyne Engineering, Northridge, California, USA) was inserted into the facemask. The flow signal from the pneumotachograph was integrated to give volume (Validyne CD280: Validyne Engineering). From a sideport on the pneumotachograph, mouth pressure was measured using a differential pressure transducer (range: $\pm 100 \mathrm{~cm} \mathrm{H} \mathrm{H}_{2} \mathrm{O}, \mathrm{MP} 45$, Validyne Engineering). The signals were amplified (Validyne CD280: Validyne Engineering) and displayed in real time on a computer (Dell Inspiron) running Labview software (version 4.0), with $100 \mathrm{~Hz}$ analogue to digital sampling (DAO 16XE-50; National Instruments, Austin TX, USA). Occlusions were made at end inspiration, which was identified from the flow signal. The distal end of the pneumotachograph was briefly occluded manually. Only occlusions during which there was no flow, a mouth pressure plateau of at least $100 \mathrm{~ms}$ in duration and a linear flow-volume plot after the occlusion was terminated were considered acceptable and analysed. Crs was calculated from the inspiratory volume and the pressure plateau and related to body weight. The time constant of the respiratory system was calculated from the linear part of the flow volume plot, and Rrs were given by the time constant divided by the Crs. The mean Crs and Rrs results were calculated from at least five technically acceptable occlusions. The mean intrasubject coefficients of variability of the Crs and Rrs measurements were $12 \%$ and $11 \%$, respectively.

Following neonatal unit discharge, infants were followed prospectively. For the purposes of this study, we assessed their outcomes in their first RSV season. The parents were asked to contact the research team when their infant was symptomatic with signs consistent with an LRTI: cough, wheeze and/or shortness of breath. ${ }^{12}$ In addition, parents were telephoned every 2 weeks by researchers to ascertain whether their infant had been or was symptomatic. A researcher visited the home on every occasion that an infant had an LRTI, and a nasopharyngeal aspirate (NPA) was obtained. NPAs were also obtained from all infants admitted to hospital with an LRTI. Real-time reverse transcription-PCR was performed on the NPAs for nine viruses (RSV A and B, human metapneumovirus, rhinovirus, influenza A and $B$, and parainfluenza 1-3) in three multiplexes with a monoplex varicella-zoster virus (VZV) RNA internal control.

The multiplexes tested were:

Multiplex 1: influenza A and B and human metapneumovirus

Multiplex 2: parainfluenza virus types 1, 2 and 3

Multiplex 3: RSV A, RSV B and human rhinovirus

Monoplex: VZV RNA internal control.

The primers were all used at $5 \mathrm{pmol}$, and the probes at $1 \mathrm{pmol}$, respectively (see Supplementary table online).

The samples were tested using a Rotor-Gene 6000 (Qiagen, Crawley, UK) and the following conditions: (1) hold at $50^{\circ} \mathrm{C}$ for $15 \mathrm{~min}$; (2) hold at $95^{\circ} \mathrm{C}$ for $15 \mathrm{~min}$; and (3) 50 cycles of (a) step $1,95^{\circ} \mathrm{C}$ hold for $30 \mathrm{~s}$; (b) step $2,57^{\circ} \mathrm{C}$ hold for $30 \mathrm{~s}$, acquiring to cycle A (FAM, Cy5, JOE, ROX).

Adenovirus (DNA virus) was tested by real-time PCR in monoplex with the VZV RNA internal control (also a monoplex). The adenovirus primers were used at $10 \mathrm{pmol}$ and the probe at 2 pmol. The VZV internal control was used as for the multiplexes above. The samples were tested using a Rotor-Gene 6000 (Qiagen) and the following conditions: (1) hold at $95^{\circ} \mathrm{C}$ for $15 \mathrm{~min}$; and (2) 45 cycles of (a) step $1,95^{\circ} \mathrm{C}$ hold for $15 \mathrm{~s}$; (b) step $2,57^{\circ} \mathrm{C}$ hold for $20 \mathrm{~s}$, acquiring to cycle A (Cy5, ROX); and (c) step $3,65^{\circ} \mathrm{C}$ hold for $20 \mathrm{~s}$.

The internal control was derived from a plasmid construct consisting of a 147 bp fragment of Promega's pGEM-T (Promega UK Ltd, Southampton, UK) vector with the VZV forward and reverse primer sequences incorporated into the $5^{\prime}$ and $3^{\prime}$ ends forming a chimeric molecule, amplified by the VZV primers and detected by a sequence-specific TaqMan probe (Applied Biosystems, Warrington, UK), based on the original method described previously. ${ }^{13}$ To produce the RNA internal control, the fragment was cloned back into the pGEM-T vector, reverse transcribed with Promega's Riboprobe in vitro Transcription System, as described by the manufacturer, isolated, purified and quantified using standard molecular biology techniques. Each reaction included the internal control to monitor each sample for potential inhibition and to avoid reporting false-negative results. In a true negative, the internal control will amplify, whereas if the internal control fails to amplify, this would indicate inhibitory compounds in the sample which were preventing the amplification of the nucleic acid from any potential pathogen in the sample.

The neonatal notes were examined to determine if the infant had been exposed to antenatal steroids and/or antenatal infection (maternal positive blood culture, histologically proven chorioamnionitis, maternal temperature with a positive culture from a high vaginal swab or rupture of the membranes of duration $>24$ h. ${ }^{14}$ Data were also collected regarding administration of surfactant, whether the infant had had a postnatal infection (positive blood culture or suspected clinical infection with a raised C-reactive protein, increased or decreased neutrophil count and/or decreased platelet count ${ }^{15}$ ), developed bronchopulmonary dysplasia (BPD; oxygen dependency beyond 28 days) and/or received palivizumab. During the study period, only infants with BPD who had required supplementary oxygen until at least 1 week before neonatal intensive care unit (ICU) discharge and were being discharged during the RSV season were given palivizumab. The decision to admit infants during the follow-up period was made by the clinicians caring for the infants, who were unaware of the lung function test results. 


\section{Analysis}

The infants were divided into four groups: (i) infants who never had a symptomatic LRTI-no LRTI; (2) infants who had symptomatic LRTI(s), but no virus was detected from an NPA-viral-negative LRTI; (3) infants who had at least one LRTI, from which RSV was detected from the NPA-RSV LRTI; and (4) infants who had symptomatic LRTI(s) with viruses other than RSV detected from the NPA-other viral LRTI.

Data were tested for normality using the Shapiro-Wilk test. Birth weight and FRC results were normally distributed and differences were assessed for statistical significance using the one-way analysis of variance (ANOVA); all the other results were not normally distributed, hence differences were assessed for statistical significance using the Kruskal-Wallis test. Multiple comparisons were performed using a one-way ANOVA with a post hoc Bonferroni test for multiple comparisons or the Kruskal-Wallis test with a post hoc Dunn test for multiple comparisons. The relationship between Rrs and the occurrence of either RSV LRTI or other viral LRTI correcting for gestational age was assessed using analysis of covariance. The threshold for significance was $p<0.05$. To give an estimate of the value of lung function as a predictor of subsequent severe RSV LRTI (ie, hospitalisation) we calculated and compared areas under receiver operating characteristic curves (AUCs) using SPSS version 15 for those factors which differed significantly between infants with RSV LRTI who were and were not admitted. Statistical analysis was performed using GraphPad Prism (version 5).

\section{Sample size}

In our previous study ${ }^{9}$ we found a difference in the lung function results equivalent to $1 \mathrm{SD}$ between the groups. Our planned sample size, therefore, was 160 infants to ensure we had at least 20 infants in each of the RSV and other viral LRTI groups to give $90 \%$ power at the $5 \%$ level to detect a difference in the lung function results equivalent to at least $1 \mathrm{SD}$ between each of those two groups and the no LRTI group.

\section{RESULTS}

A total of 251 infants were eligible for inclusion in the study (figure 1). Seventy-four parents did not consent to their infant taking part in the study, and nine parents consented but then defaulted from follow-up. One infant had a tracheostomy and lung function measurements were not possible, and five infants had unsatisfactory lung function recordings. One infant died before discharge and two infants died shortly after discharge.

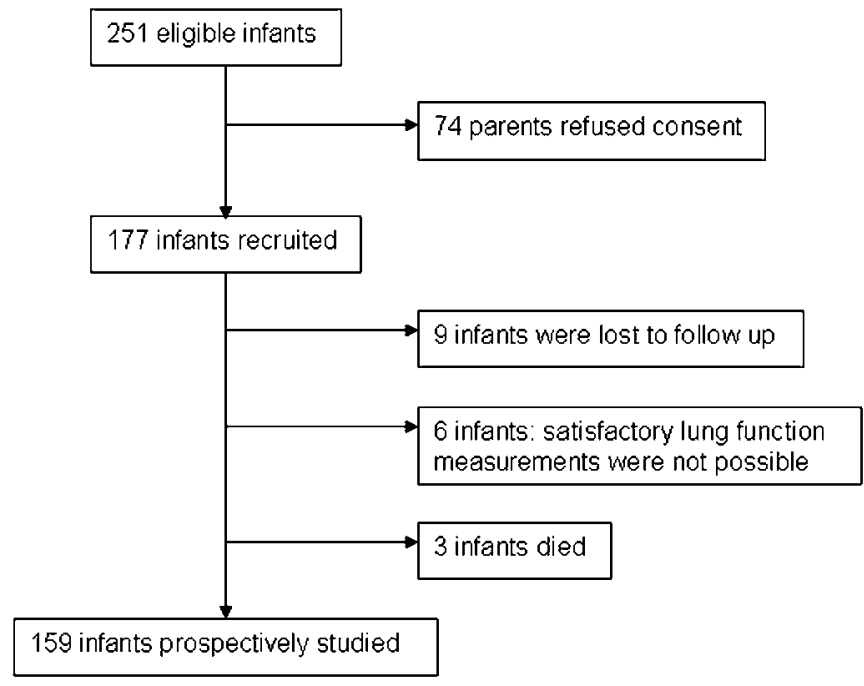

Figure 1 Consort diagram of recruitment.

The 159 (88 males) infants who completed the study had a median gestational age of 34 weeks (IOR 31-35) and a median birth weight of $1890 \mathrm{~g}$ (IOR 1446-2308); none was lost during the follow-up period. The infants who completed the study were of lower gestational age (median gestational age 34 weeks vs 35 weeks, $p=0.03$ ) and birth weight (median birth weight $1890 \mathrm{~g}$ vs $2132 \mathrm{~g}, \mathrm{p}=0.08$ ) than those who did not take part. Overall, $32(20 \%)$ mothers had had an antenatal infection and $110(69 \%)$ had received antenatal steroids. Thirty-two (20\%) infants had received surfactant, 55 (35\%) infants had had a postnatal infection and $16(10 \%)$ developed BPD. Seven infants received palivizumab (table 1 ). One of the seven infants who received palivizumab was admitted to hospital and that was because of an RSV LRTI. Two infants had a nosocomial infection due to rhinovirus while on the neonatal unit; in both cases this was after lung function testing. One of the infants subsequently developed an RSV LRTI and their results were analysed in the RSV group; the other did not subsequently have an RSV infection and their results were analysed in the other viral LRTI group.

The only significant differences in the demographics of the four groups were with regard to birth weight $(p=0.02)$ and the number of infants receiving surfactant $(p=0.03)$ (table 1$)$. Those differences were due to the other viral LRTI group being of lower

Table 1 Demographic data

\begin{tabular}{|c|c|c|c|c|c|}
\hline & No LRTI & Viral-negative LRTI & RSV LRTI & Other viral LRTI & p Value \\
\hline $\mathrm{n}$ & 86 & 15 & 27 & 31 & \\
\hline Gestational age (weeks) & $34(32-35)$ & $34(31-35)$ & $33(30-34)$ & $33(29-35)$ & 0.11 \\
\hline Birth weight $(\mathrm{g})$ & $2070(1605-2413)$ & $2026(1586-2312)$ & $1830(1335-2065)$ & $1565(1261-2152)$ & 0.02 \\
\hline Antenatal smoking & $14(16 \%)$ & $2(13 \%)$ & $4(15 \%)$ & $7(23 \%)$ & 0.82 \\
\hline Antenatal steroids & $52(60 \%)$ & $11(73 \%)$ & $22(81 \%)$ & $25(81 \%)$ & 0.07 \\
\hline Surfactant & $12(14 \%)$ & $2(13 \%)$ & $6(22 \%)$ & $12(39 \%)$ & 0.03 \\
\hline Parental atopy & $43(50 \%)$ & $6(40 \%)$ & $9(33 \%)$ & $12(42 \%)$ & 0.42 \\
\hline Day care & $2(2 \%)$ & $0(0 \%)$ & $1(4 \%)$ & $2(6 \%)$ & 0.61 \\
\hline Number of siblings & $1(0-2)$ & $2(1-2)$ & $1(0-2)$ & $1(0-2)$ & 0.17 \\
\hline Palivizumab & $1(1 \%)$ & $1(7 \%)$ & $1(4 \%)$ & $4(13 \%)$ & 0.05 \\
\hline
\end{tabular}

Data are expressed as median (IOR) or $n(\%)$

LTRI, lower respiratory tract infection; RSV, respiratory syncitial virus. 
Table 2 Number of viruses detected by PCR

\begin{tabular}{lcc}
\hline Viruses & $\begin{array}{c}\text { RSV LRTI } \\
\text { group }\end{array}$ & $\begin{array}{c}\text { Other viral } \\
\text { LRTI group }\end{array}$ \\
\hline RSV A & 8 & 0 \\
RSV B & 19 & 0 \\
Rhinovirus & 8 & 21 \\
Adenovirus & 4 & 8 \\
Human metapneumovirus & 1 & 5 \\
Influenza A & 1 & 3 \\
Influenza B & 1 & 2 \\
Parainfluenza 1 & 3 & 3 \\
Parainfluenza 2 & 0 & 1 \\
Parainfluenza 3 & 0 & 6 \\
No. of occasions a virus was not detected & 4 & 12 \\
\hline
\end{tabular}

Data are displayed as the number of occasions a virus was detected.

LTRI, lower respiratory tract infection; RSV, respiratory syncitial virus.

birth weight $(p<0.05)$ and a greater proportion of them having received surfactant $(p<0.05)$ than the no LRTI group.

On 138 occasions, 73 infants had an LRTI and on 94 occasions a virus was detected (table 2). Twenty-seven infants had at least one RSV-positive LRTI (some also had other viral LRTIs); 11 required hospital admission (nine for RSV LRTI (one of those infants required intensive care) and two for non-respiratory causes). The infants who were admitted compared with those who were not were born at an earlier gestational age (median (IOR) 30 (29-33) weeks vs 34 (33-35) weeks, $p=0.004)$, were of lower birth weight (1446 (1020-1815) g vs 1852 (1515-2100) g, $\mathrm{p}=0.047)$, had required more days of ventilation on the neonatal unit $(6(1.3-220)$ days vs $0(0-1)$ days, $\mathrm{p}=0.011)$ and more days of supplementary oxygen on the neonatal unit $(7$ (1-49) days vs $0(0-1)$ days, $\mathrm{p}=0.011)$, and a greater proportion had had BPD (33\% vs $0 \%, p=0.013)$. They, however, had not had more NPAs taken $(p=0.22)$. The age at LRTI presentation also did not differ significantly between those who were and were not admitted, the mean age in both groups being 4.2 months $(p=0.91)$.

Thirty-one infants suffered at least one other viral LRTI, but not an RSV LRTI; three required hospital admission (two for LRTI and one for non-respiratory causes). There were no significant differences between those who were and were not admitted with regard to gestational age at birth, birth weight, duration of ventilation and supplementary oxygen on the neonatal unit, BPD, number of NPAs taken and age at LRTI presentation. Fifteen infants had LRTIs with no virus identified; four required hospital admission (two for LRTI and two for nonrespiratory causes). Eighty-six infants did not have an LRTI and four required hospital admission (all for non-respiratory causes). Eleven infants had at least one dual infection and two had a triple infection (RSV A/human metapneumovirus/rhinovirus and RSV B/parainfluenza 1/adenovirus). The infant with the triple infection due to RSV A/human metapneumovirus/rhinovirus was the only infant who was admitted to an ICU.
The only significant differences between the lung function results of the four groups (table 3 and figure 2), even after correcting for gestational age, were the 'raw' Crs results $(\mathrm{p}=0.031)$, but post hoc testing demonstrated no significant differences between the groups. The infants who were admitted to hospital with an RSV LRTI compared with those who were not had higher Rrs results (median (IOR) $88(76-100) \mathrm{cm} \mathrm{H}_{2} \mathrm{O} / \mathrm{l} / \mathrm{s}$ vs $\left.70(63-76) \mathrm{cm} \mathrm{H} \mathrm{H}_{2} \mathrm{O} / \mathrm{l} / \mathrm{s}\right)(\mathrm{p}=0.033)$ and lower median Crs $(2.4$ (1.9-2.8) $\mathrm{ml} / \mathrm{cm} \mathrm{H}_{2} \mathrm{O}$ vs 3.0 (2.2-3.6) $\mathrm{ml} / \mathrm{cm} \mathrm{H}_{2} \mathrm{O}, \mathrm{p}=0.027$ ), but the FRC results were similar $(\mathrm{p}=0.13)$. Calculation of the AUCs regarding hospitalisation for RSV LRTI revealed: gestational age AUC $=0.829(p=0.005)$, birth weight $A U C=0.718(p=0.063)$, days in oxygen $A U C=0.791(p=0.13), B P D A U C=0.650(p=0.20)$, Rrs $\mathrm{AUC}=0.735 \quad(\mathrm{p}=0.045)$ and uncorrected Crs $\mathrm{AUC}=0.756$ $(p=0.029)$. There were no significant differences between the AUCs for gestational age and Rrs $(p=0.499)$ or for gestational age and uncorrected Crs $(p=0.548)$ The infants who were admitted to hospital with another viral LRTI compared with those who were not had higher Rrs results (only two infants were admitted; their $\mathrm{Rrs}$ results were 103 and $129 \mathrm{~cm} \mathrm{H}_{2} \mathrm{O} / \mathrm{l} / \mathrm{s}$ vs (66-92) $80 \mathrm{~cm} \mathrm{H}_{2} \mathrm{O} /$ $1 / \mathrm{s}(\mathrm{p}=0.039))$ and tended to have lower compliance results (1.6 and $1.9 \mathrm{ml} / \mathrm{cm} \mathrm{H}_{2} \mathrm{O}$ vs $2.8(2.4-3.7) \mathrm{ml} / \mathrm{cm} \mathrm{H}_{2} \mathrm{O}, \mathrm{p}=0.052$, but the FRC results were similar $(\mathrm{p}=0.67)$.

\section{DISCUSSION}

There were no overall significant differences in the lung function results between infants who developed an RSV or other viral LRTI and those who had no LRTI in the RSV season. Those results might appear to conflict with those in the literature. 679 (table 4) In the study of Young et al, ${ }^{6}$ however, virology results were only available for the two infants who were admitted to hospital, both of whom were RSV positive; the other 15 infants who were not admitted had a doctor diagnosis of bronchiolitis. ${ }^{6}$ There were no significant differences in the Rrs or Crs results between their groups and there was only a non-significant trend for those who subsequently developed bronchiolitis to have a lower $\mathrm{V}_{\max }$ FRC than those who did not $(\mathrm{p}=0.065)$. In another study of term-born infants, ${ }^{7}$ no virological results were reported and comparison was made between infants who did and did not subsequently develop a wheezing respiratory illness. The risk of having a wheezing illness was 3.7 times higher among infants whose values for total respiratory conductance were in the lowest third, but this was not statistically significant $(p=0.06)^{7}$ Those results ${ }^{7}$ could be interpreted as indicating that diminished lung function predicts those who wheeze with an LRTI rather than those predisposed per se to a viral LRTI. In a very prematurely born group, we demonstrated that Rrs was significantly higher in those who subsequently developed an RSV LRTI compared with the rest of the cohort. ${ }^{9}$ The infants included in that study had worse lung function than those presently examined, reflecting that a greater proportion had had BPD; six of the 15 infants with RSV LRTI had required hospital

Table 3 Lung function results

\begin{tabular}{|c|c|c|c|c|c|}
\hline & No LRTI $(n=86)$ & Viral negative LRTI $(n=15)$ & RSV LRTI (n=27) & Other viral LRTI $(n=31)$ & p Value \\
\hline Postmenstrual age (weeks) & $35.9(35.3-36.5)$ & $36.1(35.7-37.1)$ & $35.9(35.3-36.6)$ & $36.1(35.6-37.5)$ & 0.16 \\
\hline Weight $(\mathrm{g})$ & $2115(1871-2418)$ & $2178(1978-2477)$ & $1972(1830-2170)$ & $1970(1829-2336)$ & 0.10 \\
\hline $\mathrm{FRC}(\mathrm{ml} / \mathrm{kg})$ & $25.9(23.4-28.0)$ & $24.7(21.4-27.4)$ & $23.8(21.3-27.8)$ & $24.2(22.1-28.6)$ & 0.54 \\
\hline $\mathrm{Crs}\left(\mathrm{ml} / \mathrm{cm} \mathrm{H} \mathrm{H}_{2} \mathrm{O} / \mathrm{kg}\right)$ & $1.55(1.31-1.71)$ & $1.47(1.19-1.53)$ & $1.35(1.08-1.59)$ & $1.23(1.08-1.73)$ & 0.11 \\
\hline $\operatorname{Crs}\left(\mathrm{ml} / \mathrm{cm} \mathrm{H} \mathrm{H}_{2} \mathrm{O}\right)$ & $3.2(2.6-3.6)$ & $3.4(2.5-3.9)$ & $2.8(2.1-3.6)$ & $2.9(2.2-3.2)$ & 0.031 \\
\hline $\operatorname{Rrs}\left(\mathrm{cm} \mathrm{H}_{2} \mathrm{O} / \mathrm{l} / \mathrm{s}\right)$ & $70(60-84)$ & $69(62-83)$ & $74(64-81)$ & $82(67-92)$ & 0.12 \\
\hline
\end{tabular}

Data are expressed as median (range).

Crs, compliance of the respiratory system; FRC, functional residual capacity; LTRI, lower respiratory tract infection; Rrs, resistance of the respiratory system; RSV, respiratory syncitial virus. 


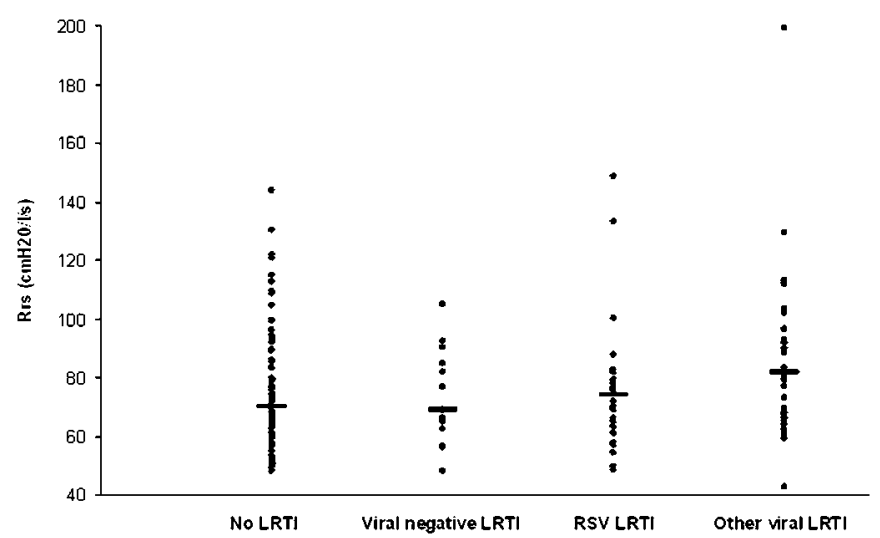

Figure 2 Resistance of the respiratory system (Rrs) results related to viral lower respiratory tract (LRTI) status. Individual data are shown. The horizontal lines represent the medians of each group. RSV, respiratory syncitial virus.

admission. In this study, which included infants with a broader range of gestational ages, we highlight the Rrs results to be significantly higher in those infants who were admitted to hospital with an RSV or another viral LRTI-that is, they were likely to have had more severe infection.

We have demonstrated that infants with RSV or other viral LRTIs who were hospitalised compared with those who were not had significantly worse premorbid lung function-that is, higher Rrs results and significantly lower Crs results (not corrected for body weight). In the RSV LRTI groups, those who were admitted to hospital compared with those who were not were born at a significantly earlier gestational age and of lower birth weight, required significantly longer durations of ventilation and supplementary oxygen and a significantly greater proportion had developed BPD. It is, therefore, not surprising that they had significantly worse lung function at 36 weeks PMA. Comparison of the AUCs demonstrated no significant differences in the AUCs for gestational age and either Rrs or Crs-that is, they performed similarily. We thus suggest lung function testing at 36 weeks PMA may not only indicate a group at highest risk, but also indicates a mechanism by which prematurely born infants develop severe RSV LRTIs - that is, they are more likely to develop a severe RSV LRTI if they have significantly poorer premorbid lung function.
Lung function was assessed by measuring Crs, Rrs and FRC. The FRC and Crs results were corrected for body weight, as length can be difficult to measure accurately in small infants. In the 'thinnest' infants, FRC and Crs may be overestimated when a weight correction is used. We have also given the uncorrected data, and the median Crs, but not FRC results, differs significantly in the RSV group between those who were and were not admitted, further emphasising they had worse lung function. Rrs results are not routinely corrected for either body weight or length and differed significantly in both the RSV and the other viral groups between those who were and were not admitted. There was a wide range of results, reflecting the wide spread of gestational ages of the infants we examined. The low intraobserver coefficients of variability, however, demonstrate our results to be reliable. We studied the infants in the neonatal ICU and were unable to measure $\mathrm{V}_{\max }$ FRC. A criticism, therefore, of our study is that we cannot exclude that there may be differences in small airway function between the two groups. Our study, however, has a number of strengths. We prospectively followed a large cohort of infants and thus had sufficient numbers to be able to appropriately compare results from infants with RSV LRTI or other viral LRTI with those with no LRTI. The infants, however, were only prospectively followed during the RSV season and it is possible the infants suffered other viral infections subsequently. In addition, only two infants were admitted to hospital with other viral LRTIs and thus it would be important to determine whether our results are replicated in a larger number of infants admitted to hospital with 'other' respiratory viral infections. We used PCR techniques that could detect 10 respiratory viruses. The PCR techniques are more sensitive than conventional virus isolation or immunoflourescence techniques for the diagnosis of respiratory virus infections in children. ${ }^{16-18}$ A further strength of our study is that parents were asked to contact us whenever their infant was symptomatic and, in addition, they were reminded by 2 -weekly telephone calls. As a consequence, we were able to document LRTIs not only in hospital but also in the community.

In conclusion, our results suggest that, overall, prematurely born infants are not predisposed by diminished premorbid lung function to RSV or other viral LRTIs, but rather they are predisposed to severe LRTIs-that is, those that require hospitalisation.

Table 4 Previous studies reporting lung function prior to lower respiratory tract infections (LRTIs) in infancy

\begin{tabular}{|c|c|c|c|c|c|c|c|c|}
\hline References & $\begin{array}{l}\text { Sample } \\
\text { size }\end{array}$ & $\begin{array}{l}\text { GA at } \\
\text { birth }\end{array}$ & $\begin{array}{l}\text { PMA at } \\
\text { assessment } \\
\text { (weeks) }\end{array}$ & Viral identification & Lung function test results & & & \\
\hline \multirow[t]{3}{*}{ Young et $a l^{6}$} & 253 & Term & 45 & $\operatorname{RSV}(n=2)$ & & Bronchiolitis $(n=10)$ & Control $(n=236)$ & $\mathrm{p}$ Value \\
\hline & & & & & $\operatorname{Rrs}\left(\mathrm{cm} \mathrm{H} \mathrm{H}_{2} \mathrm{O} / \mathrm{s}\right.$ ) & $60(5)$ & $56(10)$ & NS \\
\hline & & & & & $\mathrm{Crs}\left(\mathrm{ml} / \mathrm{cm} \mathrm{H} \mathrm{H}_{2} \mathrm{O} / \mathrm{kg}\right)$ & $1.4(0.1)$ & $1.4(0.03)$ & NS \\
\hline \multirow[t]{3}{*}{ Martinez et al ${ }^{7}$} & 124 & Term & 48 & Virology not reported & & LRTI with wheeze $(n=24)$ & No LRTI $(n=88)$ & $\mathrm{p}$ Value \\
\hline & & & & & $\mathrm{FRC} \mathrm{He}(\mathrm{ml})$ & $97.1(20.8)$ & $103.2(16.7)$ & 0.63 \\
\hline & & & & & $\mathrm{V}_{\max } \mathrm{FRC}(\mathrm{ml} / \mathrm{s})$ & $118.6(51.2)$ & $131.2(47.9)$ & 0.50 \\
\hline \multirow[t]{4}{*}{ Broughton et al ${ }^{9}$} & 39 & 28 & 36 & $\operatorname{RSV}(n=15)$ & & RSV LRTI $(n=15)$ & No RSV LRTI $(n=24)$ & $\mathrm{p}$ Value \\
\hline & & & & & Rrs $\left(\mathrm{cm} \mathrm{H} \mathrm{H}_{2} \mathrm{O} / / \mathrm{s}\right)$ & $126(62)$ & $89(28)$ & 0.01 \\
\hline & & & & & $\operatorname{Crs}\left(\mathrm{ml} / \mathrm{cm} \mathrm{H} \mathrm{H}_{2} \mathrm{O} / \mathrm{kg}\right)$ & $1.0(0.5)$ & $1.0(0.5)$ & 0.82 \\
\hline & & & & & $\mathrm{FRC} \mathrm{He} \mathrm{(ml/kg)}$ & $22(4)$ & $22(3)$ & 0.94 \\
\hline
\end{tabular}

Data are demonstrated as mean (SD).

Crs, compliance of the respiratory system; FRC, functional residual capacity; GA, gestational age; He, helium dilution; NS, non-significant; Rrs, resistance of the respiratory system; RSV, respiratory syncitial virus: $T_{m e} / T_{E}$, the time to maximal expiratory flow as a proportion of total expiratory time. 
Funding SBD is supported by the National Institute for Health Research Biomedical Research Centre at Guy's and St Thomas' NHS Foundation Trust/King's College London. TW was, and MA is, supported by Abbott Laboratories.

Competing interests Abbott Laboratories who supported TW and presently support MA market palivizumab, a monoclonal antibody against RSV.

Ethics approval This study was conducted with the approval of the Research Ethics Committee of King's College Hospital NHS Trust.

Provenance and peer review Not commissioned; externally peer reviewed.

\section{REFERENCES}

1. Stokes GM, Milner AD, Hodges IG, et al. Lung function abnormalities after acute bronchiolitis. J Pediatr 1981;98:871-4.

2. Hall CB, Hall WJ, Gala $\mathrm{CL}$, et al. Long-term prospective study in children after respiratory syncytial virus infection. J Pediatr 1984;105:358-64.

3. Noble V, Murray M, Webb MS, et al. Respiratory status and allergy nine to 10 years after acute bronchiolitis. Arch Dis Child 1997;76:315-19.

4. Korppi M, Piippo-Savolainen E, Korhonen K, et al. Respiratory morbidity 20 years after RSV infection in infancy. Pediatr Pulmonol 2004;38:155-60.

5. Broughton S, Sylvester KP, Fox G, et al. Lung function in prematurely born infants after viral lower respiratory tract infections. Pediatr Infect Dis J 2007;26:1019-24.

6. Young S, O'Keeffe PT, Arnott J, et al. Lung function, airway responsiveness, and respiratory symptoms before and after bronchiolitis. Arch Dis Child 1995;72:16-24.

7. Martinez FD, Morgan WJ, Wright AL, et al. Diminished lung function as a predisposing factor for wheezing respiratory illness in infants. N Engl J Med 1988;319:1112-17.

8. Martinez FD, Morgan WJ, Wright AL, et al. Initial airway function is a risk factor for recurrent wheezing respiratory illnesses during the first three years of life. Group Health Medical Associates. Am Rev Respir Dis 1991;143:312-16.
9. Broughton S, Bhat R, Roberts A et al. Diminished lung function, RSV infection, and respiratory morbidity in prematurely born infants. Arch Dis Child 2006;91:26-30.

10. Clark SJ, Beresford MW, Subhedar NV, et al. Respiratory syncytial virus infection in high risk infants and the potential impact of prophylaxis in a United Kingdom cohort. Arch Dis Child 2000:83:313-16.

11. Hey EN. The relation between environmental temperature and oxygen consumption in the new-born baby. J Physiol 1969;200:589-603.

12. Martinez FD, Wright AL, Taussig LM, et al. Asthma and wheezing in the first six years of life. N Engl J Med 1995;332:133-8.

13. Hodgson J, Zuckerman M, Smith M. Development of a novel internal control for a real-time PCR for HSV DNA types 1 and 2. J Clin Virol 2007:38:217-20.

14. Schrag SJ, Zell ER, Lynfield R, et al; The Active Bacterial Core Surveillance Team. A population-based comparison of strategies to prevent early-onset group $B$ streptococcal disease in neonates. N Engl J Med 2002:347:233-9.

15. Fowlie PW, Schmidt B. Diagnostic tests for bacterial infection from birth to 90 days—a systematic review. Arch Dis Child Fetal Neonatal Ed 1998:78 F92-8.

16. Kuypers J, Wright N, Ferrenberg J, et al. Comparison of real-time PCR assays with fluorescent-antibody assays for diagnosis of respiratory virus infections in children. J Clin Microbiol 2006;44:2382-8.

17. van de Pol AC, van Loon AM, Wolfs TF, et al. Increased detection of respiratory syncytial virus, influenza viruses, parainfluenza viruses, and adenoviruses with real-time PCR in samples from patients with respiratory symptoms. J Clin Microbio 2007:45:2260-2.

18. Bonroy C, Vankeerberghen A, Boel A, et al. Use of a multiplex real-time PCR to study the incidence of human metapneumovirus and human respiratory syncytial virus infections during two winter seasons in a Belgian paediatric hospital. Clin Microbiol Infect 2007:13:504-9.

\section{Journal club}

\section{A role for cigarette fumes in the development of emphysema through reduced alveolar cell proliferation and upregulation of apoptosis}

This paper describes a molecular mechanism for the loss of alveolar tissue in cigarette smokeinduced lung injury. Under the influence of adverse environmental conditions including hypoxia, the intracellular stress protein Rtp801 is transcribed. This study sought to demonstrate that Rtp801 downregulates the kinase mammalian target of rapamycin (mTOR) which is responsible for alveolar cell proliferation and upregulates the apoptotic and inflammatory pathways through the activation of the transcription factor nuclear factor kappa B (NF-KB).

Increased levels of Rtp801 were measured in alveolar cells of patients with chronic obstructive pulmonary disease compared with healthy individuals through histological staining and electrophoresis. Western blotting studies in mice showed significantly increased Rtp801 levels following exposure to cigarette smoke for 7 days. Mice treated with the antioxidant $\mathrm{N}$-acetyl-L-cysteine followed by exposure to smoke showed no overall increase in Rtp801 levels. Overexpression of Rtp801 in mice without exposure to smoke led to significant alveolar apoptosis. Rtp801 knock-out mice were protected from alveolar inflammatory and apoptotic changes in the presence of smoke. Inhibition of NF- $\mathrm{KB}$ activity resulted in decreased levels of inflammation and apoptosis.

These results confirm the role of this cellular stress response in alveolar damage and provide further evidence for a genetic component to emphysema.

- Yoshida T, Mett I, Bhunia AK, et al. Rtp801, a suppressor of mTOR signalling, is an essential mediator of cigarette smokeinduced pulmonary injury and emphysema. Nat Med 2010;16:767-73.

\section{East}

Correspondence to M East, AcFY2, Department of Microbiology, Leeds Teaching Hospitals NHS Trust, Old Medical School, Leeds General Infirmary, Great George Street, West Yorkshire, UK; m.east@doctors.net.uk 